\title{
Performance Comparison between Salient and Segmental Rotors Single-Phase FEFSM Using Non-Overlap Windings for Home Appliances
}

\author{
M. F. Omar'*, E. Sulaiman'², H. A. Soomro ${ }^{3}$ L. I. Jusoh ${ }^{4}$ \\ ${ }^{1,2,3,4}$ Faculty of Electrical and Electronic Engineering, Universiti Tun Hussein Onn Malaysia, 86400 Parit Raja, Johor, Malaysia. \\ *Corresponding authors E-mail: fairoz.omar@yahoo.com
}

\begin{abstract}
Field excitation flux switching machines (FEFSMs) in which their torque performance produced by interaction between armature and field excitation (FE) coils have been widely designed for various applications. In this regard, three-phase salient rotor FEFSM with overlap windings is considered the most suitable candidate for high speed applications because of their advantages of flux controllability, and robust due to single piece of rotor structure. However, the overlap windings cause a high copper loss, hence efficiency of the motor becomes low and higher stack length. Besides, the salient rotor structure is found to produce low torque performance due to the longer flux path in stator and rotor yielding weak flux linkage. In this paper, a new single-phase FEFSM using non-overlap windings between armature coils and FE coils is proposed. Both non-overlap windings FEFSMs with salient and segmental rotors have been designed using JMAG Designer version 15 and the investigation process is conducted via $2 \mathrm{D}$ finite element analysis. The proposed motor performances verification has been done by comparing the results of flux linkage, flux line and distribution, flux strengthening, various torque capability, and torque-power versus speed characteristics. As a conclusion, single-phase non-overlap windings FEFSM using segmental rotor with power, torque and speed capabilities of $277.5 \mathrm{~W}, 0.91 \mathrm{Nm}$ and 2,899 rpm, respectively considered as the best candidate for low torque high speed applications.
\end{abstract}

Keywords: Field Excitation; Flux Switching Machine; Non-overlap Windings; Salient Rotor; Segmental Rotor; Single-Phase.

\section{Introduction}

Currently, most of the commercial applications that require low torque and high speed performances such as blower, exhaust fan, compressor motors, pumps, and fan are using induction motors (IMs) as their main prime mover [1], [2]. The example of structure and specifications of single-phase IMs used in commercial applications are illustrated in Figure 1 and Table 1, respectively [3]. Induction motor's rotor can be either wound type or squirrel-cage type. For the wound type, winding is located on the rotor and stator, while for squirrel-cage winding is placed only on stator. Consequently, rotor not robust, and heat temperature of rotor is easily increased resulting in heat accumulated in the middle of motor [4]. In order to improve torque performance and efficiency of electric motors, flux switching motors (FSMs) originated from the blend of switched reluctance motor and inductor alternator is introduced.

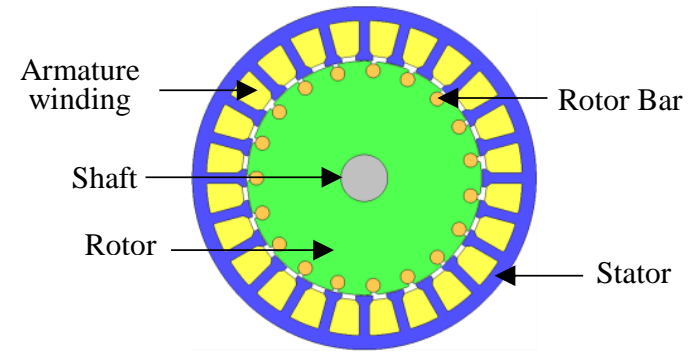

Fig. 1: Structure of induction motor
The first concept of FSM was founded and published in mid1950s. The main features of FSM is all active parts such as coil windings and permanent magnet are placed on stator, single piece of rotor structure, and free from brush maintenance [5]. Over the past three decades, numerous FSM topologies have been developed for various applications, ranging from low-cost domestic appliances, automotive, wind power, aerospace, and others [6]. Generally, FSM can be categorised into three groups: permanent magnet flux switching motor (PMFSM), field excitation flux switching motor (FEFSM), and hybrid excitation flux switching motor (HEFSM). Both PMFSM and FEFSM have only permanent magnet (PM) and field excitation coil (FEC), respectively as their main flux sources, while HEFSM combines both PM and FEC as

Table 1: Single-phase induction motor specifications

\begin{tabular}{|c|c|}
\hline Items & Parameters \\
\hline Input voltage (V) & 240 \\
\hline Frequency (Hz) & 50 \\
\hline Rated power (W) & 60 \\
\hline Rated torque (Nm) & 0.4 \\
\hline Range of speed (rpm) & $1455-1465$ \\
\hline Stator outer diameter (mm) & 75 \\
\hline Rotor outer diameter (mm) & 44.5 \\
\hline Air gap distance $(\mathrm{mm})$ & 0.25 \\
\hline Weight $(\mathrm{kg})$ & 0.91 \\
\hline
\end{tabular}


its main flux source. Compare with other FSMs, FEFSM has preferences of low cost, simple construction, magnet-less machine, and variable flux control capabilities reasonable for different performances. Besides, FEFSMs have the advantage of cost-saving materials as the PM on stator used in PMFSM is replaced by excitation from FECs [7].

Figure 2 illustrates the basic operation of FEFSM. Considering Figure 2(a), the excitation of the field and armature windings at positive current creates a flux vector in the north-westerly direction and north-easterly direction, respectively. The combined flux generated by the two coils caused a flux moving vertically upwards and the rotor aligned itself with a pair of vertical stator. Moreover, Figure 2 (b) illustrates the current in the armature winding is reversed, while the FEC winding continues being excited in the same direction by the effect of the $180^{\circ}$ flux shifting from west-south. The result from the $180^{\circ}$ shifting makes the rotor tends to align with the stator poles based on the flux movement in a westerly direction through horizontal stator poles. Each reversal of current directions in the armature causes the stator flux vector to switch between horizontal and vertical directions [8], [9].

Recently, a three-phase FEFSM with salient rotor structure has been introduced with their advantages of easy rotor temperature removal and controllable FEC magnetic flux particularly suitable for applications that require high torque, and high power performances [10]. Besides, the single piece of salient rotor structure with robust performance at high speed condition give an advantage to the FEFSM [11]. While, single-phase FEFSM with overlap windings technique for low cost and low torque applications such as axial fan and pump have been introduced in 2003 [12]. Regarding [13] and [14], motor with overlap windings have higher torque density due to an improved pitch factor. In addition, the motor with overlap windings has also high average torque and power performances due to high winding inductance and high flux linkage [15]. Despite of their have merits of high winding inductance, cost saving, magnet-less machine, and variable flux control capabilities reasonable for various commercial applications, the single-phase FEFSMs structure and winding technique can further be enhanced to improve their torque performance and efficiency. In these regards, a new structure of non-overlap windings singlephase FEFSM using salient rotor (SalRoN) and segmental rotor (SegRoN) are proposed. The proposed motors have 12 slots for copper windings, and 6 rotor poles. 2D finite element analysis (FEA) through JMAG Designer version 15 is used to analyse the flux linkage, flux distribution, flux line, flux strengthening, backemf, torque capability, and torque-power versus speed characteristics of the proposed motor.

\section{Parameter Configuration and Design Meth- odology of FEFSM}

The machine configuration for non-overlap windings single-phase FEFSM using salient and segmental rotors are demonstrated in Figure 3. From the figure, the design has 6 segmental rotor poles in the middle of stator with non-overlap windings between armatures and FECs coils. The windings coils of FECs are placed in between of armature coil, while the winding configurations of
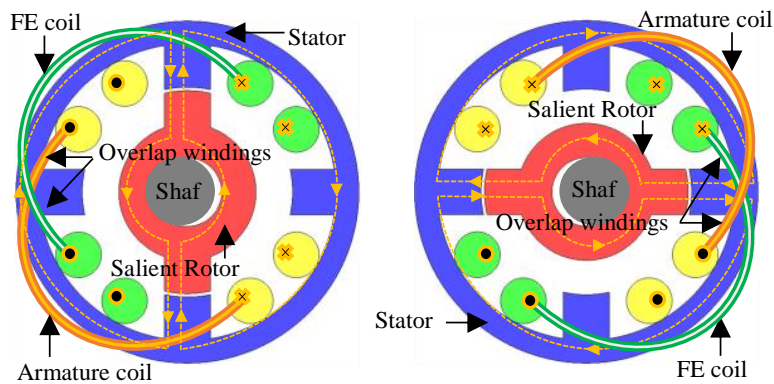

Fig. 2: Basic principle of FEFSM both winding coils are in clockwise polarity and counter clockwise polarity. Table 2 shows the design specifications and parameters for the proposed machines. From Figure 3(a) the width of the rotor gear is set at $5 \mathrm{~mm}$, equal to the width of the stator gear to avoid leakage flux. While, rotor span of $26^{\circ}$ as illustrated in Figure 3(b) is set based on arc length of segmental rotor tooth and the outer radius of the segment rotor. The main function of the salient and segmental rotors is to modulate, and change the magnetic flux polarisation in armature coils, and this also shows the elementary

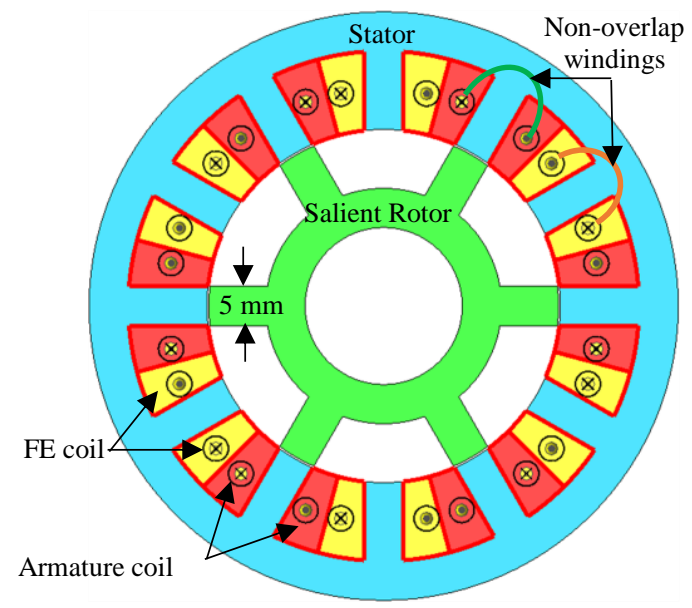

(a) FEFSM using salient rotor (SalRoN)

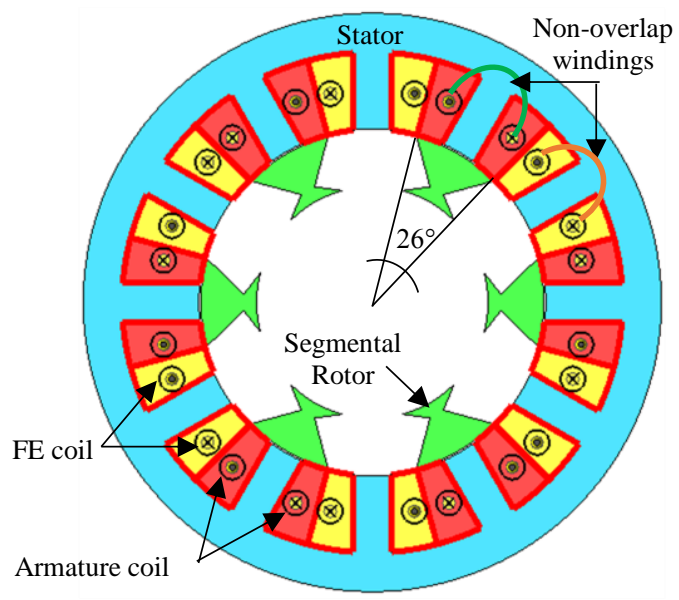

(b) FEFSM using segmental rotor (SegRoN)

Fig. 3: Structure of the proposed non-overlap winding FEFSMs

Table 2: Design Specifications and Parameters

\begin{tabular}{|c|c|c|}
\hline Parameters & SalRoN & SegRoN \\
\hline Phase type & \multicolumn{2}{|c|}{1} \\
\hline Slot number & \multicolumn{2}{|c|}{12} \\
\hline Pole number & \multicolumn{2}{|c|}{6} \\
\hline Outer stator diameter (mm) & \multicolumn{2}{|c|}{75} \\
\hline Inner stator diameter (mm) & \multicolumn{2}{|c|}{45} \\
\hline Stator back inner radius (mm) & \multicolumn{2}{|c|}{5} \\
\hline Armature coil area $\left(\mathrm{mm}^{2}\right)$ & \multicolumn{2}{|c|}{47} \\
\hline FEC area $\left(\mathrm{mm}^{2}\right)$ & \multicolumn{2}{|c|}{47} \\
\hline Outer rotor diameter $(\mathrm{mm})$ & \multicolumn{2}{|c|}{44.5} \\
\hline Inner rotor diameter $(\mathrm{mm})$ & 30 & 20 \\
\hline Salient rotor tooth width $(\mathrm{mm})$ & - & 5 \\
\hline Segmental rotor span (degree) & 26 & - \\
\hline Space of air gap $(\mathrm{mm})$ & \multicolumn{2}{|c|}{0.5} \\
\hline Stack length (mm) & \multicolumn{2}{|c|}{20.3} \\
\hline FEC number of turn & \multicolumn{2}{|c|}{93} \\
\hline Armature coil number of turn & \multicolumn{2}{|c|}{93} \\
\hline
\end{tabular}


principles of FEFSMs operation. The split ratio of rotor outer diameter and stator outer diameter is set to be $59 \%$ as standard motor design requirement. In short, equal stator back inner and stator pole widths are introduced so that the flux linkage is predictable to reduce flux saturation as well as provide enough space for flux to flow in the stator yoke with equal magnetic flux distribution.

Design methodology of the proposed non-overlap windings FEFSMs have three main sections in the implementation of this study: Geometry editor, JMAG designer and simulation test. The Geometric editor and JMAG designer sections are the process of designing each motor structure and the internal setup of the proposed motors, respectively. Finally, the performances comparison between salient and segmental rotors is made based on the results of flux linkage, flux distribution, flux line, flux strengthening, back-emf, various torque capability, and torque-power versus speed characteristics.

\section{Performances Comparison of SalRoN and SegRoN}

\subsection{Flux linkages}

Figure 4 shows the comparison of FEC and armature flux linkages between SalRoN and SegRoN. The FEC flux linkage is plotted when maximum FEC current density, $\left(J_{E}\right)$ of $30 \mathrm{~A} / \mathrm{mm}^{2}$ and armature current density, $\left(J_{A}\right)$ is zero, while armature flux linkage is plotted when $J_{A}$ is set to a maximum of $30 \mathrm{~A}_{\mathrm{rms}} / \mathrm{mm}^{2}$ and $J_{E}$ is zero Clearly, the core source of flux in FEFSM which is FEC flux linkage of $0.0435 \mathrm{~Wb}$ has produced from SegRoN design is 11 times higher than SalRoN design. While, for the armature flux profile, SalRoN has produced flux linkage of $0.1172 \mathrm{~Wb}, 63.2 \%$ higher than SegRoN design. However, the armature flux profile of both designs show unbalance between positive and negative cycles due to the high flux leakage occurs when magnetics flux flows from stator to rotor as illustrated in Figure 5 and Figure 6. In addition,

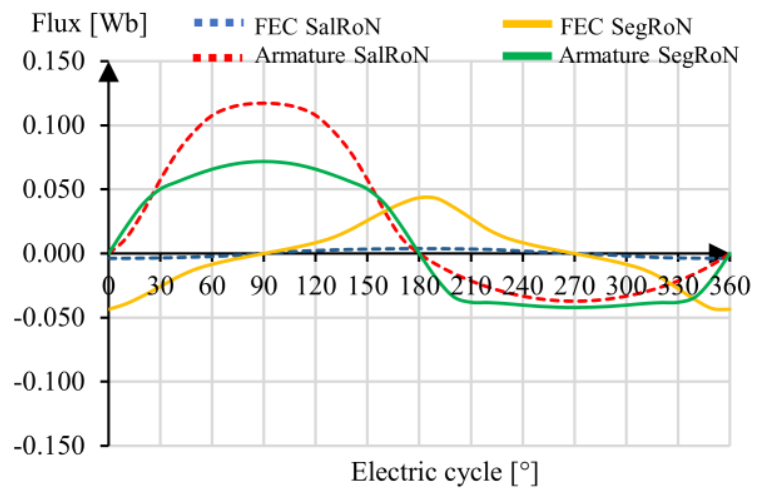

Fig. 4: Flux linkage of SalRoN and SegRoN

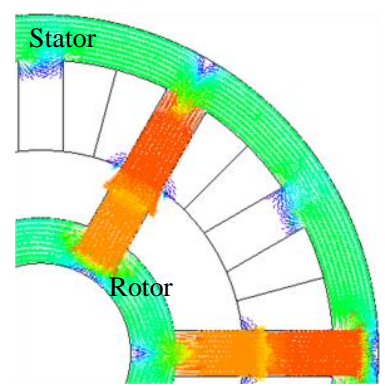

(a) Rotor at $90^{\circ}$

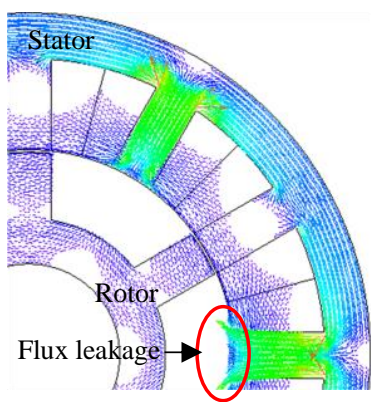

(b) Rotor at $270^{\circ}$
Fig. 5: Flux distribution of SalRoN both designs show the FEC flux linkage lead $90^{\circ}$ of armature flux linkage, ensure the proposed motor is working based on standard operating principle of single-phase motor.

\subsection{Flux line}

The flux line formed by FECs excitation with the maximum $J_{E}$ of $30 \mathrm{~A} / \mathrm{mm}^{2}$ for the proposed motors are illustrated in Figure 7. From Figure 7(b), the magnetic flux of segmental rotor is linked between two stator teeth and single segmental rotor tooth, while the magnetic flux of salient rotor as demonstrated in Figure 7(a) is linked between three teeth of the stator and two teeth of rotor poles proving that the segmental rotor produces shorter magnetics flux path than the salient rotor. In short, the segmental rotor tooth structure assists flux to flow in shorter route and increase the flux strength, hence producing high torque.

\subsection{Flux strengthening}

The proposed non-overlap windings FEFSMs have the privilege of being able to control the flux by diversifying the value of the incoming DC supply into the FEC windings. Thus, to examine the flux flexibility, $J_{E}$ is varied from $0 \mathrm{~A} / \mathrm{mm}^{2}$ to $30 \mathrm{~A} / \mathrm{mm}^{2}$, and $J_{A}$ is set to $0 \mathrm{~A}_{\mathrm{rms}} / \mathrm{mm}^{2}$. Fig. 8 shows maximum flux linkage at $J_{E} 0$ to

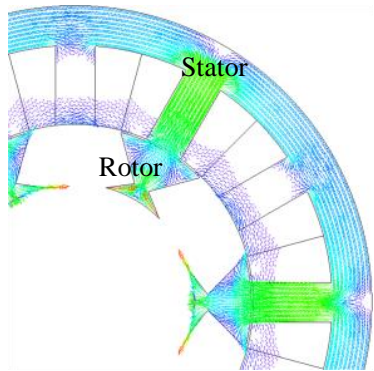

(a) Rotor at $90^{\circ}$

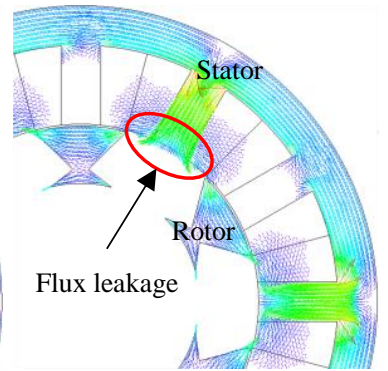

(b) Rotor at $270^{\circ}$
Fig. 6: Flux distribution of SegRoN

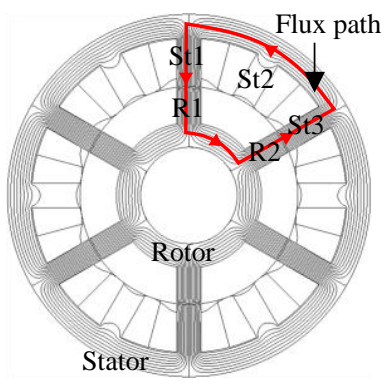

(a) SalRoN

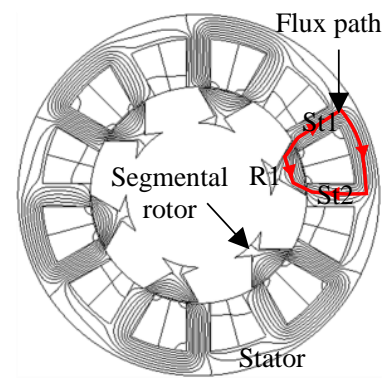

(b) SegRoN
Fig. 7: Flux line of the proposed non-overlap windings FEFSMs

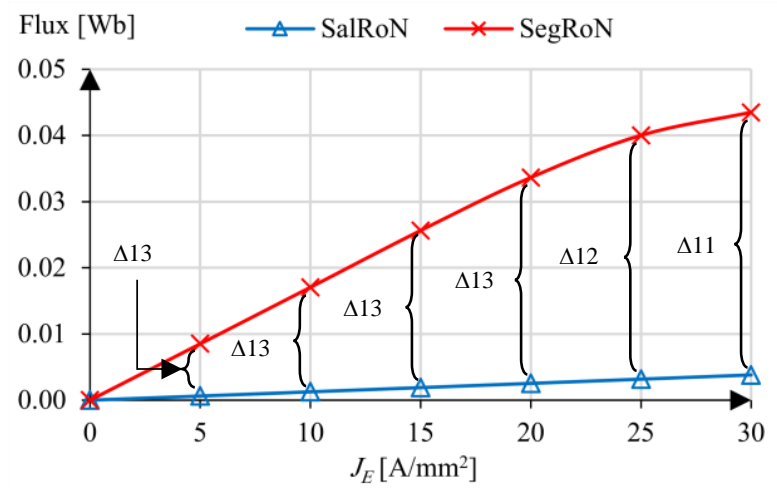

Fig. 8: Flux strengthening of the proposed non-overlap windings FEFSMs. 
$30 \mathrm{~A} / \mathrm{mm}^{2}$. Obviously, from the figure flux linkages of SegRoN and SalRoN designs are increased linearly until the flux reach at maximum of $0.0435 \mathrm{~Wb}$ and $0.0038 \mathrm{~Wb}$, respectively at $J_{E}$ of 30 $\mathrm{A} / \mathrm{mm}^{2}$ and prove the FEC flux linkage analysis. Maximum flux linkage of SegRoN design has 13, 12 and 11 times higher than SalRoN design when the $J_{E}$ of $5 \mathrm{~A} / \mathrm{mm}^{2}$ to $20 \mathrm{~A} / \mathrm{mm}^{2}, J_{E} 25$ $\mathrm{A} / \mathrm{mm}^{2}$ and $J_{E}$ of $30 \mathrm{~A} / \mathrm{mm}^{2}$, respectively.

\subsection{Back-emf Profile}

Figure 9 shows the back-emf profile of the proposed non-overlap windings FEFSMs. From the figure, the highest back-emf of $1.9 \mathrm{~V}$ and 13.4 V have been recorded from SalRoN and SegRoN designs, respectively. The back-emf profile of SalRoN has lower back-emf compared to the SegRoN design due to less total harmonic distortion (THD) as illustrated in Figure 10. From Figure 9 and Figure 10 , it can be concluded that the back-emf profile have been disrupted due to high THD, especially on the $3^{\text {rd }}$ and $5^{\text {th }}$ harmonics.

\subsection{Torque Capability at Various $J_{A}$ and $J_{E}$}

Various torque capabilities of the proposed non-overlap windings FEFSMs at various $J_{E}$ and $J_{A}$ are plotted in Figure 11. Obviously, the torque increases parallelly with increase of $J_{A}$ and $J_{E}$. At the top of $J_{A}$ and $J_{E}$, the $S e g R o N$ design has produced torque of 0.91 $\mathrm{Nm}$, almost 10 times higher than SalRoN design. It proved that the shorter flux path produced by segmental rotor of SegRoN has increased the flux strength, hence producing high torque. In addition, torque capability of SalRoN at $J_{A}$ is $10 \mathrm{~A}$ rms $/ \mathrm{mm}^{2}$, the torque becomes constant when the $J_{E}$ is high, while at high $J_{A}$, the torque keeps increasing until the optimum torque is achieved.

\subsection{Torque-Power Versus Speed Characteristics}

The torque-power versus speed characteristics of the non-overlap windings FEFSMs have been performed by diversifying $J_{A}$ from 0 to $30 \mathrm{~A}_{\mathrm{rms}} / \mathrm{mm}^{2}$ and change the armature current phase angle as illustrated in Figure 12. It can be seen that the highest torque of

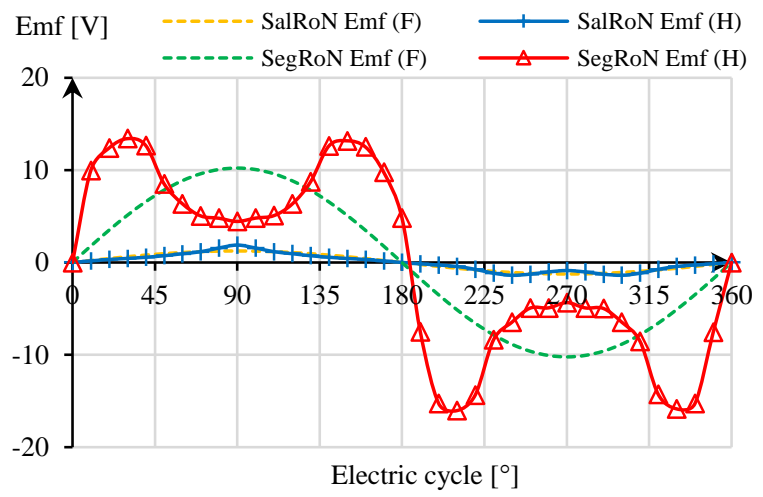

Fig. 9: Back-Emf of the proposed non-overlap windings FEFSMs

\section{Magnitude}

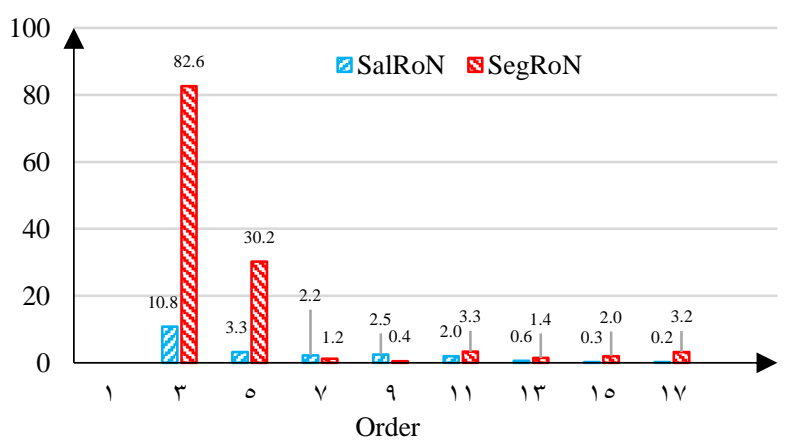

Fig. 10: THD versus harmonic order

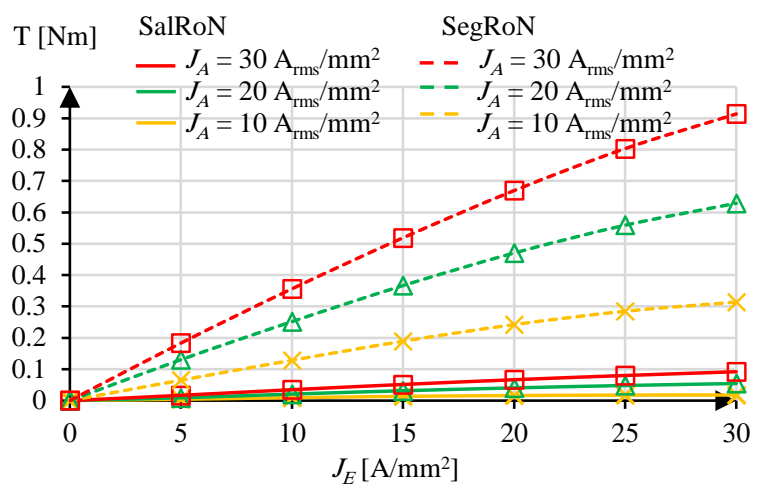

Fig. 11: Torque characteristics of FEFSM using segmental rotor

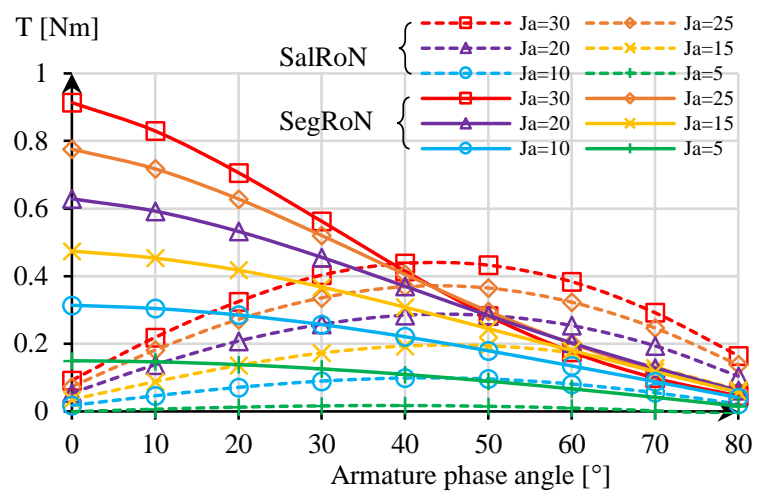

Fig. 12: Torque versus phase angle characteristics

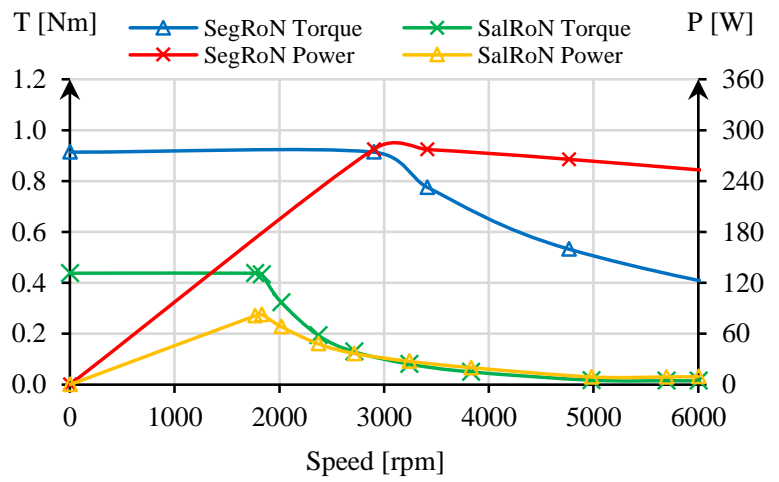

Fig. 13: Torque-power versus speed characteristics of the proposed non-overlap windings FEFSMs.

SalRoN under maximum $J_{E}$ of $30 \mathrm{~A} / \mathrm{mm}^{2}$ has been obtained when the armature phase angle is set to $40^{\circ}$. While, the highest torque of SegRoN is achieved when armature phase angle is set to $0^{\circ}$.

Torque-power versus speed characteristics of SalRoN and SegRoN designs are plotted in Figure 13. Clearly, SegRoN design has produced highest torque and power of $0.91 \mathrm{Nm}$ and $277.5 \mathrm{~W}$, respectively. The initial torque at based speed of 2,899 rpm starts to decrease when exceed speed of 2,304 rpm. From the figure, torque and power characteristics of SegRoN are 2 and 3 times higher than SalRoN design. Meanwhile, the highest torque of SalRoN is $0.44 \mathrm{Nm}$ is achieved at speed of $1,769 \mathrm{rpm}$ and the corresponding power is $81.1 \mathrm{~W}$. In addition, at a high speed of $6,000 \mathrm{rpm}$, torque of $0.4 \mathrm{Nm}$ generated by SegRoN is almost equal to the highest torque of SalRoN.

\section{Conclusion}

A new structure of single-phase non-overlap windings FEFSMs using salient and segmental rotors have been presented. The procedure to design the FEFSMs has been clearly explained. The analyses of the non-overlap windings FEFSMs such as flux link- 
age, flux distribution, flux line, back-emf, flux strengthening, various torque capability, and torque-power versus speed characteristics have been investigated. Based on 2D FEA, the SegRoN has short flux path, high FEC flux linkage, and high torque characteristics. However, back-emf and armature unbalance flux linkage profiles of SegRoN can be further improved in future by design refinement and optimization. As a conclusion, the proposed SegRoN is considered as the best candidate for low torque-high speed applications due to the good initial performances of torque, power and speed of $0.91 \mathrm{Nm}, 277.5 \mathrm{~W}$ and 2,899 rpm, respectively.

\section{Acknowledgement}

This work was funded by Ministry of Education Malaysia (MOE) under FRGS Vot. 1651 grant thru Universiti Tun Hussein Onn Ma-laysia (UTHM).

\section{References}

[1] Abdel-Rahim N, \& Shaltout A, "Operation of single-phase induction motor as two-phase motor", IECON Proc. (Industrial Electron. Conf., Vol. 2, (2002), pp. 967-972.

[2] Sobhani S, Yaghobi H \& Samakoosh M, "Optimize efficiency and torque in the single-phase induction motor by adjusting the design parameters", 12th Int. Conf. Environ. Electr. Eng. EEEIC 2013, 2013, pp. 237-241

[3] "Stand Fan SF1802 Instruction Manual"

[4] Liu CS, Hwang JC \& Chen PC, "Improvement of driver efficiency for the single-phase motor", IEEE Int. Symp. Ind. Electron., (2012) pp. 664-667.

[5] Mazlan MMA, Sulaiman E \& Kosaka T, "Design study of single phase outer-rotor hybrid excitation flux switching motor for hybrid electric vehicles", Proc. 2014 IEEE 8th Int. Power Eng. Optim. Conf. PEOCO 2014, No. c, (2014), pp. 138-143.

[6] Sulaiman E, "Design Studies on Less Rare-Earth and High Power Density Flux Switching Motors with Hybrid Excitation/Wound Field Excitation for HEV Drives", (2012), pp. 11-25.

[7] Nguyen HQ, Jiang JY \& Yang SM, "Design of a 12-slot 7-pole wound-field flux switching motor for traction applications", in IEEE International Conference on Industrial Technology (ICIT), (2016), pp. 1275-1280.

[8] Pollock C \& Wallace M, "The flux switching motor, a DC motor without magnets or brushes", Conf. Rec. 1999 IEEE Ind. Appl. Conf. Thirty-Forth IAS Annu. Meet. (Cat. No.99CH36370), Vol. 3, (1999), pp. 1980-1987.

[9] Jenal M, Hamzah SA, Khan F, Soomro HA \& Sulaiman E, "Performance investigations of flux switching machines for light weight electric vehicles", 2015 IEEE Conf. Energy Conversion, CENCON 2015, (2016), pp. 78-83.

[10] Pollock C et al., "Flux-switching motors for automotive applications", IEEE Trans. Ind. Appl., Vol. 42, No. 5, (2016), pp. 1177-1184.

[11] Mongellaz R, Sellier F, Chishko SD, Paulides JJH \& Lomonova E A, "Co-Energy-Based Lookup Table Model for DC-Excited FluxSwitching Motor: Study at Vehicle Level”, in 2015 IEEE Vehicle Power and Propulsion Conference, VPPC 2015 - Proceedings, (2015), pp. 1-8

[12] Pollock C, Pollock H \& Brackley M, "Electronically Controlled Flux Switching Motors: A Comparison with an Induction Motor Driving an Axial Fan”, in Industrial Electronics Society (IECON), vol. 3, (2003), pp. 2465-2470.

[13] Xiao F et al., "Winding configuration design of flux-switching PM motors based on magnetic gearing principle", 2015 IEEE Int. Magn. Conf. INTERMAG 2015, Vol. 58, No. 11, (2015), pp. 5101,.

[14] Li D, Qu R, Li J, Xu W \& Wu L, "Synthesis of flux switching permanent magnet machines", IEEE Trans. Energy Convers., Vol 31, No. 1, 2016, pp. 106-117.

[15] Shao L, Hua W, Zhu ZQ, Zhu X, Cheng M \& Wu Z, "A Novel Flux-Switching Permanent Magnet Machine With Overlapping Windings", IEEE Trans. Energy Convers., Vol. 32, No. 1, 2017, pp. 172-183. 